\title{
ENSEÑAR Y CATEQUIZAR EL MANDATO DE LOS PROFESORES JESUITAS DE LA CORDOBA DEL TUCUMAN EN EL XVII
}

\author{
Dra. María Cristina Vera de Flachs ${ }^{1}$ \\ Universidad de Córdoba-Argentina \\ Grupo de Investigación HISULA \\ vera@onenet.com.ar
}

Recepción: 10/09/2008

Evaluación: 06/10/2009

Aceptación: 30/10/2009

Articulo de Reflexión

\section{RESUMEN}

En este artículo se rescata el desempeño de los primeros docentes jesuitas de la Universidad de Córdoba del Tucumán durante el Siglo XVII, en tanto ellos, con sus ideales, utopías, ordenamiento académico y forma de trasmitir conocimientos, fueron protagonistas fundamentales en el proceso educativo de los jóvenes americanos. En todas las cátedras que dictaron, cumplieron con el mandato de la Ratio e inculcaron los valores de la Orden siendo un ejemplo vivo de esa pedagogía que intentaba formar al hombre en ciencia y religión.

La metodología producción historiográfica que, por otra parte, es escasa en Latinoamérica. Estas reflexiones seguramente servirán de impulso para posteriores discusiones acerca de temas relacionados con ellos y permitirán encausar futuras investigaciones dentro del marco de la historia comparada.

Dichos escritos trascienden los relatos personales o los de la propia Compañía de Jesús y evidencian un profundo conocimiento del lugar que habitaron, en tanto nos informan de los progresos de la época, del estado de la educación, de la situación de las

\footnotetext{
1 Doctora en Historia, Licenciada en Historia por la Facultad de Filosofía y Humanidades, Profesora Titular de Historia Social Contemporánea. Facultad de Derecho y Ciencias Sociales. Universidad Nacional de Córdoba, Investigadora Principal del Consejo Nacional de Investigaciones Científicas y Tecnológicas. [CONICET]. Integrante del grupo de investigación Historia y Prospectiva de la Universidad Latinoamericana HISULA.
} 
misiones, de la historia de la región, de las lenguas y tradiciones, del clima, de las riquezas naturales, etc., pero, también, de los problemas internos de la Orden, de la falta de vocaciones, de la relajación de los colegiales, de las materias que enseñaban y los textos utilizados. En fin, dieron cuenta de todo lo que hacía referencia a su sistema de enseñanza, lo que demuestra que dichos escritos son una cantera inagotable para los estudiosos del período; pero eso es otra historia.

Palabras clave: Jesuitas, Universidad de Córdoba, Profesores, Enseñar, Catequizar

\title{
JESUITS PROFESSORS' PROTAGONISM WITH THEIR EDUCATIONAL PROPOSAL CARRIED OUT AT CORDOBA DEL TUCUMAN UNIVERSITY IN THE 17 TH CENTURY
}

\author{
Dra. María Cristina Vera de Flachs \\ Universidad de Córdoba-Argentina \\ HISULA Research Group \\ vera@onenet.com.ar
}

\begin{abstract}
In this article, the performance of the first Jesuits professors of the Universidad de Córdoba del Tucumán during 17th century is rescued, inasmuch as, they with their ideals, utopias, academic ordering and ways to transmit their knowledge, were fundamental protagonists in the educational process of American youth. Trough their chairs, they dictated, they fulfilled the mandate of the Ratio and thought, and the values of the Order that became an alive example of that pedagogy that they tried to form men in science and religion.
\end{abstract}

Key words: Jesuits, Universidad de Córdoba, Professors, teaching, catechizing. 
"Diríjase la intención particular del profesor, tanto en las lecciones cuando se ofrezca ocasión, como fuera de ellas, a mover a sus oyentes al servicio y amor de Dios y de las virtudes, con las que es preciso agradarle; y a que todos sus estudios los enderecen a este fin" ${ }^{2}$.

\section{INTRODUCCIÓN}

Desde sus orígenes, la Universidad ha sido la agremiación de maestros y alumnos en torno al saber, su búsqueda y su trasmisión. En esta ocasión fuimos convocados a rescatar y analizar el desempeño de los primeros docentes jesuitas de la universidad de Córdoba en el siglo XVII, en tanto ellos fueron protagonistas fundamentales en el proceso educativo de muchos jóvenes americanos. Esto justifica nuestra preocupación por pensar a estos actores que reflejaron en sus actividades diarias el mundo del saber de su época, al tiempo que sus sueños y desazones nos permiten vislumbrar las funciones y disfunciones de la institución.

Lejos de reconstruir en tono heroico los avatares que vivieron, que fueron muchos por otra parte, aspiramos marcar la trayectoria de ese grupo de profesores dentro del claustro universitario cordobés haciendo hincapié en sus ideales, utopías, ordenamiento académico y forma de trasmitir sus conocimientos a los discípulos que formaron. No es fácil llegar a dar respuesta a estos planteos para esta centuria en tanto se debe bucear en distintas fuentes. Sin embargo, tenemos esperanza que si avanzamos en este sentido, afianzaremos una nueva línea de producción historiográfica que, por otra parte, es escasa en Latinoamérica. Estas reflexiones seguramente servirán de impulso para posteriores discusiones acerca de temas relacionados con ellos y permitirán encausar futuras investigaciones dentro del marco de la historia comparada.

\section{Especificaciones Metodológicas y Análisis de Fuentes}

La primera pregunta que nos hicimos fue ¿Cómo estudiarlos? ¿Con qué fuentes contamos? ¿Qué método utilizar? ¿Cómo hacer para no caer en nuestro análisis en caminos ya trillados? Es decir, como ver el comportamiento de los docentes sin caer en perspectivas ajenas sino teniendo en cuenta nuestra realidad. Nuestra intención es considerar sus actuaciones como parte de la Universidad pero teniendo en cuenta que si bien ellos son integrantes de la sociedad de su tiempo no tienen un comportamiento homogéneo. Esto nos exige conocer de que estamos hablando, ¿Cuál era el entorno en que están insertos? ¿Cuál era la idea de universidad, gusto por el saber y forma de trasmitir que tenían? ¿Cuál era el momento político, económico y social en que vivieron?

\footnotetext{
2 IV. Reglas comunes a todos los profesores de las Facultades Superiores. Método y programa de los estudios de la Compañía de Jesús, San Ignacio de Loyola. Constituciones de la Compañía de Jesús. Cuarta parte principal: Del instruir en letras y en otros medios de ayudar a los prójimos los que se retienen en la Compañía.
} 
Para contestar los interrogantes debemos en primer lugar partir de la propia formación y experiencia y definir el marco histórico que pretendemos analizar; luego, se debe recurrir a las fuentes, para poder indagar lo máximo posible. Ellas provienen obviamente de la propia Compañía, de sus Constituciones y de otra documentación entre la que se destaca la Ratio atque Institutio Studiorum Societatis Iesu o Plan de estudios de la Compañía de Jesús, en su edición de fines del siglo XVI que fue el modelo docente e instructivo que tuvieron para enseñar los jesuitas.

Del recorrido por las Cartas Anuas y las cartas de los PP. Generales a las autoridades del Colegio de Córdoba y viceversa, como así también por otro tipo de correspondencia privada o las de tipo reservado que van saliendo a la luz, podemos conocer, entre otras cosas, la labor realizada en él y llenar los vacíos de documentación sobre los primeros años de la vida universitaria en esta región. En efecto, el flujo de información entre los miembros de la Orden y Roma evidencia la preocupación que los jesuitas tuvieron en toda la centuria por la marcha de los estudios y de las misiones, de allí que compartiendo las afirmaciones del P. Morales, sostenemos que estas fuentes tienen un gran valor y abren una ventana, a través de la cual el investigador puede asomarse a la historia de la vida cotidiana de la institución.

Obviamente es imprescindible en Córdoba la consulta del Archivo General de la Universidad, de los fondos del ex Instituto de Estudios Americanistas, del Archivo del Arzobispado. Así también los de otros existentes en el país, como el Archivo General de la Nación o el del Colegio del Salvador en Buenos Aires que tiene documentación general y en particular sobre Córdoba. Del mismo modo el Archivo Nacional de Chile reúne en su sección jesuitas valiosas fuentes que nos permiten complementar algunos aspectos; pero, sin duda, las obras de los propios padres, editadas en América o Europa y los escasos cursos por ellos dictados que se conservan y han sido analizados por especialistas en el tema ayudan a comprender aún más la dedicación a la docencia de los jesuitas, en especial para el siglo XVIII.

Ciertamente se consultaron los datos diseminados en los diferentes artículos y monografías que han escrito otros historiadores a lo largo del tiempo, entre los que sobresalen los de los miembros de la propia Compañía de Jesús desde antaño. A comienzos del siglo XX, se distingue la labor realizada por los padres Pablo Cabrera, Avelino Ignacio Gómez Ferreyra, Zenón Bustos, Carlos Leonhardt, Hugo Storni, P. Grenón, Guillermo Furlong, y Joaquín de Gracia y, en esta última etapa, la de los contemporáneos Martín Morales, José del Rey Fajardo, Carlos Vázquez, etc. En otro orden merecen destacarse los trabajos de Víctor Infantes, Adrien Demoustier, Francois Charmont, Jorge E. Ganss, Marc Baldó Lacomba, Remedios Ferrero Micó o Dominique Julia. A su vez, varios investigadores argentinos han realizado importantes contribuciones sobre el período y sus actores, como por ejemplo, Juan M. Garro, Roberto Peña, Enrique Martínez Paz, Alberto Caturelli, Celina Lértora Mendoza, Ernesto Maeder, etc. Ellos, como tantos otros en los que me incluyo, se han preocupado por reflexionar sobre la cuestión que analizamos. Es imposible mencionar a todos los que de una u otra manera abordaron el tema en tanto la bibliografía es abundante, aunque de dispar valor. Pero, por lo general, todos los testimonios consultados permiten conocer algunos de los 
aspectos aquí esbozados y coinciden en sus apreciaciones sobre el valor de estos hombres que se dedicaron a formar e instruir.

En síntesis, las investigaciones acerca de la historia de las universidades y sus actores durante la etapa colonial hace tiempo que abandonaron la historia institucional para abrir el campo de estudio a múltiples facetas: la historia de las ideas, de la religiosidad, de la educación, de las finanzas, de la vida cotidiana, etc. El comportamiento de estudiantes o docentes, en cambio, ha sido objeto de análisis de interés de unos pocos, por eso nuestra preocupación por el tema.

Pero, antes de avanzar, como primera medida considero necesario situarlos en la Historia de dicha Universidad con el fin de delinear el marco temporal, social y político en el que la institución estuvo inserta a lo largo de la centuria estudiada.

\section{Nace la Universidad Jesuítica}

A fines del siglo XVI la Compañía de Jesús se asentó en Córdoba despertando rápidamente expectativas positivas en la región en tanto dicha sede, junto con la de Santiago del Estero y la de Asunción, se convirtió en uno de los pilares de la nueva Provincia Jesuítica del Paraguay. En la ciudad de Córdoba se levantó el Noviciado destinado a formar los futuros sacerdotes, el que comenzó a funcionar en 1608. En 1610 el padre Diego de Torres erigió el Colegio Máximo donde dispuso impartir estudios de artes y teología para los novicios aunque dicha aspiración duró poco tiempo pues la escasez de recursos dificultó su mantenimiento por lo que, el 12 de febrero de 1612, el P. Torres abandonó Córdoba junto a maestros y alumnos para trasladarse momentáneamente al Colegio de Chile.

Pero mientras "los estudios portátiles", así llamados por el P. Lozano estuvieron en Chile, ¿qué ocurría en Córdoba? En 1613 fray Fernando de Trejo y Sanabria, obispo de Tucumán, preocupado por esa situación cedió, a través de un contrato provisional, una dotación anual de 1.500 pesos que se sacarían de los diezmos anuales, a efectos de sustentar la existencia de dos profesores de Teología, uno de Filosofía y uno de Gramática. Luego suscribió una escritura pública por la cual donaba a la Compañía, dentro del plazo de tres años, cuarenta mil pesos para sostener el Colegio de Córdoba, y se preocupó por redactar su testamento que ratificaba su compromiso anterior, lo que decidió el regreso inmediato de los que habían partido reiniciándose, en febrero de 1614 , los estudios de filosofía y de teología. ${ }^{3}$

\footnotetext{
3 El Obispo falleció en diciembre de 1614 en absoluta pobreza, razón por la que no pudo cumplir con lo prometido, sólo heredó el Colegio la estancia de Caroya tasada en doce mil pesos, 28 esclavos y unas casas al frente del Colegio, más otros bienes y adornos. VERA DE FLACHS, María Cristina y FERRERO MICO Remedios. (1996): Finanzas y poder político en las universidades hispanoamericanas, Córdoba, Del Copista, p. 24. GRACIA, Joaquín. (2006): Los Jesuitas en Córdoba. Desde la Colonia hasta la segunda Guerra Mundial, Universidad Católica, COLECCIÓN JESUITAS, córdoba, Tomo I, p. 158. La escritura de compromiso del Obispo Trejo y Sanabria y su testamento pueden verse en del FRANCO, José R, Establecimiento y progreso de los primeros estudios superiores en Córdoba. Años 1609 a 1879, 2da edición. Córdoba, 1946.
} 
En esos años, la casa contaba con unos sesenta moradores que vivían en extrema pobreza, dada la difícil situación económica de la Orden como consecuencia, entre otras causas, a que la relación con el medio y en particular con los encomenderos, era conflictiva. Ello incidió para que en estos primeros años los padres no recibieran donaciones, las que hubieran paliado el estado financiero de la misma; tema que causaba preocupación, al punto de dejarlo señalado en las cartas cursadas a las autoridades de Roma. La situación comenzó a revertirse cuando se establecieron las estancias, aunque en el primer medio siglo de existencia el sostenimiento de la institución fue motivo de desasosiego constante.

De los sesenta residentes que había al comienzo, quedaron unos 46 hacia 1616 cuando se separó el noviciado; de ellos cerca de treinta eran estudiantes: catorce pertenecían a la Compañía y los demás eran convictores o alumnos externos. Los que estudiaban teología eran siete, los de artes diez y en el seminario de latín había seis más. Sin embargo estos jóvenes no pudieron obtener grados universitarios hasta agosto de 1621, cuando un Breve apostólico del papa Gregorio XV los autorizó por diez años. Lo exiguo de la concesión fue revertida por otro Breve, esta vez del papa Urbano III, del 29 de marzo de 1634, otorgando esa facultad sin límite de tiempo, con el fin de preparar los hombres que servirían a Dios y al monarca. ${ }^{4}$ Para cumplir con estos objetivos era imprescindible la formación de sus miembros y ello se hacía en la Universidad que contaba con dos Facultades: una de Artes y, otra, de Teología. La primera con cinco años de estudios otorgaba grados de bachiller, licenciado y maestro en Filosofía o Artes y, la segunda, con cuatro años de estudios, concedía los de bachiller, licenciado y con dos años más eran promovidos al grado de doctor en Teología, título este que se confería sólo a los estudiantes ordenados sacerdotes.

\section{La Ratio Studiorum}

Como hicimos notar el método de estudio de los establecimientos educativos jesuíticos estaba descrito en la Ratio atque Institutio Studiorum Societatis Iesu, un manual eminentemente práctico, escrito a finales del XVI. ${ }^{5}$ Si bien dicho texto sufrió varias modificaciones sobre las que no entraré en detalle, es preciso recordar que el mismo describía el proceder que debía utilizar cada miembro de la Compañía en la marcha diaria de los Colegios, fuesen docentes o directivos. Todo estaba especificado: desde las funciones que debía cumplir el prefecto de estudio hasta los profesores

\footnotetext{
4 ARCHIVO GENERAL DE LA UNIVERSIDAD DE CORDOBA [en adelante AGUC], Bulas y Cédulas, 1621-1778- fs. 15, 34 y 45. Actas, 1664-1778.

5 VAZQUEZ POSADA, Carlos S.J. (2001): La Ratio, sus inicios, desarrollo y proyección, en AA.VV., La Ratio Studiorum en América Latina. Su vigencia en la actualidad, Córdoba, Universidad Católica de Córdoba, p. 78. REY FAJARDO, José de. (1999): El alma de la Ratio Studiorum y el ámbito americano" en Jesuitas 400 años en Córdoba, Córdoba, Universidad Nacional - Universidad Católica - Junta Provincial de Historia, Vol III, p. 115. Varios autores se ocuparon de la influencia de la ratio en Europa, cfr., entre otros, G.P.BRIZZI, (ed.), La "Ratio Studiorum". Modelli culturali e pratiche educative dei Gesuiti in Italia tra Cinque e Seicento, Roma, 1981.
} 
especializados cuya misión específica era educar, respetando la dignidad y personalidad de los alumnos. Así mismo se establecieron las prácticas, programas, métodos de enseñanza, formación, perfil, valores y distribución de las cátedras ${ }^{6}$. Obviamente no todos los Colegios en América concibieron y desarrollaron de la misma manera lo estipulado en la Ratio habida cuenta las marcadas diferencias entre los institutos educativos ignacianos.

Pero, sin duda, el personaje clave para la Ratio era el maestro a quien se le pedía originalidad e independencia de pensamiento, amor a la verdad por sí misma, capacidad de reflexionar, formar juicios correctos y conocimiento individual de los alumnos para ayudarlos a crecer en valores. En síntesis, como educadores debían ser competentes y a la vez, comprometidos con la formación de los jóvenes. Por eso se les encomendaba ser pacientes con éstos, siempre más inclinados a la alabanza que a la culpa, y si era preciso efectuar alguna corrección debían hacerlo de manera amable y persuasiva. En estas tierras se les recordaba permanente "que no tuviesen aversión a nadie, interesándose por los estudios del pobre de la misma manera que del rico y procurando el éxito de cada uno de sus discípulos, con el fin que pudieran lucirse en cualquier parte de Europa", según lo hacía notar la Carta Anua de 1619.

La pedagogía era el camino por el cual los profesores acompañaban al estudiante en su crecimiento y desarrollo, por eso aquellos debían ser modelos en todo sentido además de competentes en el área que se les designara; lo que implicaba que su formación debía ser continua y en conjunto con los demás colegas. "Nada se improvisa en la Ratio" . Esto en la letra, en la práctica las cartas de los padres provinciales manifiestan que muchos profesores desconocían el método o no lo aplicaban. De todos modos el sistema de la Ratio "con sus directrices flexibles y firmes" fue el método sólido y racional que predominó en el Río de la Plata en el siglo XVII y en todas las escuelas de los jesuitas. Guillermo Furlong, recuerda que:

...el método rechazaba la memoria como único fundamento del aprendizaje y adecuaba la enseñanza al ritmo del aprendizaje de cada alumno a tal punto que no se dudaba pasar a una clase más aventajada a sus compañeros y postulaban la pedagogía activa, cuya máxima era Excita que se basa en una avanzada técnica de emulación...

Dividia la clase en dos grupos que debían competir entre sí. Además dentro de cada grupo existía una jerarquía en la que se adelantaba o no según el rendimiento individual. Cada alumno tenía su émulo en el equipo contrario, de su misma jerarquía, a quien debía aventajar en las exposiciones o disputas.

\footnotetext{
6 Las diferentes versiones de la Ratio Studiorum pueden verse en la reedición crítica realizada por LUKÁCS Ladislas en la colección Monumenta Paedagogica Societatis Iesu, Roma, 19651992- El tomo 5 apareció en 1985.

7 DOMINIQUE, Julia. (1995): La cultura escolar como objeto histórico, en Historia de las Universidades Modernas. Métodos y Fuentes. MENEGUS, Margarita y GONZALEZ Enrique, México, CESU, UNAM, pp. 139-140.
} 
Se concedian premios con gran solemnidad que incentivaban aún más la competencia y el deseo de superación. ${ }^{8}$

El latín, era la lengua que usaban los estudiantes para copiar las lecciones que dictaban los maestros; práctica, por otra parte, que permitió que algunos cursos llegaran a nuestros días. Debemos reconocer que el dictado lejos de colaborar con el avance de la ciencia y el rigor al estudio era la forma más cómoda que tenían aquellos para preparar sus exámenes ya que muchas veces, se limitaban a estudiar de esos manuscritos que pasaban de mano en mano, evitando así la lectura de los libros. En esta centuria los padres se preocuparon por alentar el conocimiento de la lengua pues en los primeros tiempos estuvieron decaídos. Justamente el buen su uso de la misma y la aplicación a los estudios determinaba la permanencia del alumno en los cursos; en el caso de Córdoba su estudio se complementaba con clases de griego.

Pero también los docentes estaban obligados a prestar atención a la enseñanza religiosa y a la formación de los jóvenes según lo aconsejaban las reglas de la Compañía:

A los adolescentes que han sido confiados a la educación de la Compañia, fórmelos el profesor de modo que, juntamente con las letras vayan aprendiendo también las costumbres dignas de un cristiano. Dirija pues, su especial atención, tanto en las clases cuando se ofreciere la ocasión como fuera de ellas a preparar las tiernas mentes de los adolescentes para el servicio y amor de Dios y de las virtudes con que se les deba agradar. ${ }^{9}$

La atención a la enseñanza de la doctrina cristina y a la formación religiosa, así como las prácticas de piedad ocupaban un lugar preponderante en la Ratio. La misa diaria, la oración, el examen de conciencia, las lecturas piadosas, eran las manifestaciones que se esperaban de los estudiantes. En definitiva, piedad y letras eran las reglas que debían cumplir.

\section{Algunas Reflexiones Sobre el Papel del Claustro y las Normativas Institucionales en Córdoba}

La primera expresión normativa de la Universidad de Córdoba se remonta al 5 de mayo de 1630 cuando el vallisoletano padre Pedro de Oñate redactó las primeras disposiciones organizativas que se conocen como Ordenaciones del P. Oñate. ${ }^{10}$

8 FURLONG, Guillermo. (1933): La enseñanza racional, Buenos Aires, Espasa Calpe, 1940, pp. 33, 34 y 48. Ibídem., Los jesuitas y la cultura rioplatense, Montevideo, Impresores Urta y Curbelo.

9 Reglas comunes a todos los profesores de las Facultades Superiores. Método y programa de los estudios de la Compañía de Jesús, San Ignacio de Loyola. Constituciones de la Compañía de Jesús. Cuarta parte principal: ... Op. Cit.

${ }^{10}$ El P. Oñate nació en Valladolid el 7/I/1567 e ingresó a la Compañía en Toledo donde fue ordenado sacerdote en 1586. Pasó al Perú con el cargo de maestro de servicios donde hizo su $4^{\circ}$ voto en Julí (Puno-Perú), y, en 1614, lo designaron Provincial de la Orden del Paraguay en reemplazo del P. Diego de Torres. Tomó posesión en 1615 y fue reelecto en 1620 , permaneciendo en ese cargo hasta su reemplazo por el P. Nicolás Durán. Falleció en Lima el 31 de diciembre de 1646 a los 79 años. 
Sus 37 artículos, basados en las Constituciones de la Universidad de San Marcos de Lima, reglamentaban los estudios estipulándose, en primer lugar, que no debían admitirse en gramática a aquellos alumnos que no supiesen leer y escribir porque ello sería una falta grave que incidiría seguramente en el futuro. En segundo lugar, se especificaban las normas para seleccionar los estudiantes y la forma en que éstos debían matricularse y examinarse como así también la vestimenta que debían portar, cuestión por otra parte que preocupó a los jesuitas durante todo el período, según veremos. Respecto al personal encargado de la dirección de los estudios dispuso que estaría compuesto por un notario, cuya tarea consistía en llevar un libro de matrícula y de grados, controlar los pagos de los aranceles que debían abonar los jóvenes y tomar el juramento de obediencia al rector in licitis et honestis en lo relativo a los estudios. El bedel que hacía las veces de maestro de ceremonias para actos y paseos; el cancelario que era el que determinaba el precio de las propinas y el Rector que era la máxima autoridad.

Sin embargo su preocupación por los estudios universitarios no concluyó con estas disposiciones, él se encargó, en diversas ocasiones, de marcar el camino previsto en la ratio studiorum en vistas a lo que consideraba como la virtud principal que debían tener los candidatos que quisieran ingresar a la misión en la Provincia, como el no olvidar que debían ser apóstoles antes que nada. También señaló, en 1620, que era imprescindible que el Colegio de Córdoba contase con un prefecto de estudios que cumpliera como debía su oficio, "pues los maestros argüían con poca modestia", por lo que debía remediarse la situación a favor de los discípulos.

Las disposiciones del P. Oñate fueron revisadas y reformadas por el P. Francisco Vázquez Trujillo y en diciembre de 1651 por el P. Juan Pastor, quien legisló sobre las funciones del secretario o notario y del bedel. Pero estas modificaciones no solucionaron los problemas que se presentaban a diario como consecuencia del crecimiento de la institución, por eso era imprescindible dictar una norma específica que rigiera su vida interna.

La universidad había crecido en su primer medio siglo de vida sin embargo aun carecía de una organización permanente. La ocasión se presentó, en 1664, cuando el padre Andrés de Rada visitador y viceprovincial de la Provincia Jesuítica del Paraguay visitó Córdoba y dictó las Constituciones, las que fueron mandadas a observar por el claustro de diciembre de ese año ${ }^{11}$. Las mismas, bastante completas, eran la expresión de las ideas de su tiempo y un reflejo del rígido sistema de educación implantado por la Compañía de Jesús en todos los establecimientos que tenía bajo su dirección.

Este documento de gran trascendencia se ocupaba de la organización de la institución, administración, de las autoridades y de los deberes y obligaciones de educadores y educandos. Pero lo más importante es que antes de poner punto final a

\footnotetext{
11 Algunos autores sostienen que contaron con aprobación real en 1680. Constituciones de la Universidad por el P. Rada, copia legalizada y admitida por el claustro, A.G.U.C., Libro de claustros, $\mathrm{N}^{\circ} 1$, fs. 23 y. 45 a 140.
}

Rhela. Vol. 13. Año 2009, pp. 189 - 212 
sus constituciones el padre Rada dispuso que todos los años al inicio de los cursos el padre rector convocara a claustro a todos los doctores y maestros que se hallaren en la ciudad conjuntamente con los padres cancelario y catedráticos con el fin de consultarlos en lo que le pareciere necesario o conveniente para el buen gobierno, conservación y aumento de la Universidad.

... en orden a que guarden mejor la constitución, todos los años al principio del curso convocará el padre Rector a claustro a todos los doctores y maestros que se hallaren en la ciudad y juntamente con los padres Cancelario y Catedráticos consultará lo que le pareciere necesario o conveniente para el buen gobierno, conservación y aumento de la Universidad, para lo cual se leerán también algunas de las Constituciones más principales y cuya observancia o es más importante o necesitare más de reparo. ${ }^{12}$

Este es el origen del claustro, ese cuerpo colegiado conformado por todos los graduados, los profesores y presidido por el rector que mantuvo su vigencia a lo largo de los siglos aun cuando sufrió modificaciones en su composición y que tanta influencia ejerció en las distintas épocas de la vida universitaria.

Cuando entraba el siglo XVIII se planteó la discusión como debía estar integrado. En efecto, el 1 de marzo de 1713, en ocasión de la visita del P. Garriga viceprovincial de la provincia del Paraguay, el claustro se reunió para determinar su conformación. En esa oportunidad, se presentaron varias mociones: hubo quien opinó que debían constituirlo todos los doctores, más seis maestros los cuales debían elegirse el día de Cenizas, cada tres años, teniendo en cuenta la antigüedad de sus grados y la aptitud para votar con acierto y madurez en los puntos que hubiera que tratar; los menos consideraron que se echara la suerte como se estilaba en la Universidad de Zaragoza y, por último, otros deseaban que se reemplazaran cada dos o tres años más y que hubiese un número determinado de los que se habían graduado por pobres.

Lo cierto es que durante toda la etapa jesuítica el claustro mantuvo un estricto orden de prelación entre sus miembros, en razón del grado y antigüedad y veló por el cumplimiento de las normas. ${ }^{13}$ La votación fue en un comienzo verbal para los casos de menor importancia y escrita cuando las deliberaciones fuesen secretas; en el primer caso el rector era el último en votar mientras en el segundo lo hacía primero. A raíz que hubo infidencias en los asuntos tratados, tiempo más tarde se resolvió que los asistentes debían prestar juramento de no revelar las opiniones vertidas en los mismos, especialmente si las cuestiones eran de carácter secreto o grave. ${ }^{14}$ Para el fiel

\footnotetext{
12 A.G.U.C., Libro de claustros $\mathrm{N}^{\circ}$ 1, Constitución 91, fs. 56. VERA DE FLACHS, María Cristina. (1961): Dos siglos de gobierno, Tesis de Licenciatura en Historia, Universidad Nacional de Córdoba, Córdoba, Inédita.

13 VERA DE FLACHS, María Cristina. (1987): "El comportamiento de los claustros de la Universidad de Córdoba. 1664-1800", en Consejo Superior de Investigaciones Científicas, Universidades Españolas y Americanas, España, Comissió per al V Centenari del Descobriment D'América, Generalitat Valenciana, p. 553.

14 A.G.U.C., Libro de Claustro, 10 de noviembre de 1721.
} 
cumplimiento de esta disposición el Rector al finalizar cada reunión aclaraba lo que debía guardarse y lo que se hallaba en el juramento expresado, sin embargo esta medida fue cayendo en desuso y se produjeron infinidad de casos en las que los asistentes no la cumplieron. De todos modos cabe señalar que en el resto de la centuria el claustro veló por el cumplimiento de lo estipulado por las Constituciones del P. Rada y trató infinidad de temas como los referidos al pago de sueldos de los catedráticos, compra de libros de filosofía para ser distribuidos entre el alumnado, dispensas en caso de enfermedades familiares de cumplir con el término establecido para las pasantías. Así mismo pudo solucionar otros inconvenientes no previstos en la legislación, conservó la disciplina entre sus estudiantes y organizó la marcha de los estudios de tal forma que, en pocos años, la Universidad gozó de gran reputación como institución superior en la América española.

\section{La Marcha de los Estudios a lo Largo de la Centuria}

Durante el período de estudio la educación superior americana estuvo estrechamente vinculada a la Iglesia y en el caso del Río de la Plata a la Compañía de Jesús, quien a través de sus Constituciones definió el fin de los estudios de sus Colegios, en particular los de teología.

"Como sea el fin de la Compañía y de los estudios ayudar a los prójimos al conocimiento y amor divino y salvación de sus ánimas siendo para esto el medio más propio la Facultad de Teología , en esta se debe insistir principalmente en la universidad de la Compañía, tratándose diligentemente por muy buenos maestros a lo que toca á la doctrina escolásticas y sacra Escriptura, y también a la positiva, lo que conviene para el dicho fin, sin entrar en la parte de los Cánones que sirve para el futuro contencioso.

Y porque así la doctrina de Teología como el uso della requiere especialmente en estos tiempos, cognición, de letras de Humanidad y de las lenguas latinas, griega y hebrea, destas habrá buenos Maestros y en número suficiente...

Así mismo porque las artes o ciencias naturales disponen los ingenios para la teología y sirven para la perfecta cognición y uso de ella y también para ayudar para los fines mismos, tratarse han con la diligencia que convieney por doctos Maestros, en todo buscando la honra y gloria de Dios Nuestro Señor.

El estudio de la Medicina y Las Leyes, como más remoto a nuestro instituto, no se trata en las universidades de la Compañia o á lo menos no tomará de ella por si tal asunto. ${ }^{15}$

\footnotetext{
15 UNIVERSIDAD NACIONAL DE CÓRDOBA, Constituciones de, "Constituciones de la Compañía de Jesús, cuarta parte principal, de instruir en letras y en otros medios de ayudar a los prójimos los que se retienen en la Compañía. Cap. XII. De las facultades que se han de enseñar en las universidades de la Compañía," p. 63.
} 
Así mismo ellas también marcaron el papel que debían tener los maestros universitarios quienes no estaban obligados a seguir un autor determinado ni en teología ni en filosofía, sino a aquel que les gustara, "pues por la misericordia del Señor todos nuestros autores que han impreso [sic] tienen opiniones y doctrina buena y segura. El haber prohibido que un maestro no ponga en las conclusiones opiniones contrarias al otro, parece cosa dura y no usada..."16

En el período que la Compañía de Jesús administró los estudios universitarios en Córdoba la enseñanza se orientó sólo a la enseñanza de la teología y filosófica siendo ella, además, la que disponía de la composición del profesorado, aunque en este caso también hubo algún dominico que llegó a dictar clases. Para 1635 había en Córdoba cuatro maestros, dos de teología escolástica, uno de artes y otro que enseñaba gramática a los externos; ellos dictaron clases a unos siete estudiantes, el menor número de inscritos que hubo en esos años, lo que incidió para que las clases de filosofía se interrumpieran al finalizar esa década por falta de oyentes ${ }^{17}$. Tal vez la razón de esta disminución se debía a que la venida del padre Procurador que solía incrementar el interés de postulantes se había dilatado.

A mediados del XVI el número de profesores fue variando según la matrícula aunque, por lo general, había dos que enseñaban teología y filosofía, dos artes y, uno, gramática $^{18}$. Pero hacia 1670 la situación cambió y la Universidad estaba floreciente, como consecuencia del desarrollo económico que había conseguido la región lo que incrementó la matrícula. Para entonces, el claustro había dictado las fórmulas de los títulos que se daban, a efectos que fuesen uniformes y de un mismo tenor. Así mismo estipuló que el profesor o estudiante que faltase al tablado, teatro o al paseo a caballo, ceremonias de graduación, perdía el derecho a la propina.

En aquel tiempo en la casa había un profesor de teología moral, dos de gramática, tres de teología, dos de filosofía y uno de artes, además de incluir un hermano coadjutor para enseñar las primeras letras y un prefecto de estudios. El padre Andrés de Rada cuando visitó la casa trazó un panorama de la misma de la siguiente manera:

Esta en un floreciente estado la Universidad, sostenida por dos profesores de filosofia, otros tantos de teología, uno de teología moral, habiendo dos sujetos de los nuestros para la enseñanza de gramática, acudiendo la juventud hasta de ciudades muy remotas, lo cual es muy importante para levantar el nivel de cultura y conocimientos en estas regiones, juntamente con el de espíritu cristiano, aprendido con el trato con los nuestros. Se iguala esta a

\footnotetext{
${ }^{16}$ MORALES, Martín. (2005): A mis manos han llegado, Cartas de los PP. Generales a la Antigua provincia del Paraguay (1608-1639), Madrid Roma, Universidad Pontificia Comillas, pp. 180.

17 MAEDER, Ernesto. (1990): Cartas Anuas de la Provincia Jesuitica del Paraguay. 1632

a 1634, Buenos Aires, Academia Nacional de la Historia, p. 24.

18 A.G.U.C., Libro de los Testimonios de grados en philosophia y theología que se dan en esta Universidad del Collegio de la Compañía de Jesús. Comienza en el año 1670.
} 
las Universidades de Europa por el derecho a conferir los grados académicos, que se dan, después de severos exámenes, con mucha solemnidad. ${ }^{19}$

En efecto, los estudios prosperaban y los estudiantes que venían de regiones remotas eran, por lo general, hijos de familias distinguidas que esperaban obtener sus grados académicos para insertarse rápidamente en la administración colonial, civil o eclesiástica. En un comienzo, los cursos se dictaban durante seis meses y un día y para pasar de uno a otro había conclusiones hebdomadarias, actos anuales y otros ejercicios de los que participaban los estudiantes. En 1680 la duración de las clases se extendió a diez meses con la obligación de asistencia y en 1683 se establecieron exámenes anuales a los estudiantes de teología.

Sin duda, los jesuitas se han distinguido por enseñar filosofía y teología, la escritura sagrada y el derecho canónico, pero su preocupación mayor era que ningún estudiante volviese a su tierra sin saber teología. Según hemos mencionado, las clases se dictaban en latín que, además de ser la lengua de la Iglesia era considerada culta, en tanto en ella se redactaban los textos científicos lo que a su vez, posibilitaba el vehículo más seguro para que las ideas se difundieran. Por otra parte, ello favorecía el contacto entre alumnos y profesores y se salvaban las diferencias de idiomas, en tanto éstos últimos eran en su mayoría extranjeros. Cabe agregar que desde muy temprano lo que se publicaba en Europa podía conseguirse en Córdoba, al punto que tiempo después el Obispo Mercadillo se quejó al rey aconsejándole impedir la libre circulación de tanto escrito sobre «viajes, relatos fabulosos, obras mundanas y publicaciones extranjeras» que conspiraban, según él, contra» las buenas costumbres». Cabe preguntarnos ¿quién traía estos libros? ¿Cómo se conseguían? La Compañía de Jesús fue la gran impulsora de la introducción, tanto para sus bibliotecas como para los lectores ajenos a la Orden. En sus librerías, los textos escolares se hallaban a la venta para estudiantes. Y con el sentido universal que los caracterizó, no trajeron sólo libros que ellos publicaban generalmente en España, sino también los de origen alemán, flamenco, franceses e italianos. En 1711, por ejemplo el P. Burgés importó catorce cajones, repitiéndose la operación en 1717. Esos envíos posibilitaron que con los años la librería jesuítica se incrementara notablemente con obras de derecho, astronomía, medicina, política, ingeniería y viajes.

Al terminar el año los estudiantes se debían rendir cuentas públicamente ante los maestros de las clases escuchadas. A partir de la apertura del Colegio el Monserrat, lugar donde éstos moraban, se los examinaba previamente y si estaban suficientemente preparados se los dejaba presentar a los exámenes finales en la Universidad. Si alguno por negligencia o por torpeza de entendimiento respondía en forma regular se los apremiaba hasta que pudieran presentarse con seguridad ante los jueces. Así se mantenía la reputación de los alumnos. El P. José Peramás tiempo después, recordó que el aislamiento ayudaba a formar a los jóvenes con letras como las del Olimpo, que «no

19 BiBlioteCA DEL COLEGIO DEL SALVADOR. (2004): Cartas Anuas, 1652-1654, estante 11, fs. 93. Véase PAGE, Carlos, El Colegio Máximo de Córdoba (Argentina) según las Cartas Anuas de la Compañia de Jesús, Córdoba, Báez editores, p. 21. 
pueden ser destruidas ni por la violencia de los vientos ni por la lluvia». Así de estrictos eran los claustros estudiantiles, con clases y debates en latín.

\section{Maestros universitarios del siglo XVII, ni más ni menos}

Para conocer la trayectoria de los primeros docentes nos preguntamos: ¿quiénes fueron?, ¿de dónde venían?, ¿con qué saberes contaban y cuál era la idea de universidad que tuvieron?, ¿fueron simples repetidores o se animaron a introducir algunos cambios? y ¿cuáles eran sus lecturas y conocimientos sobre el desarrollo de la "ciencia nueva"?

Gracias a la documentación que se ha conservado hemos podido rescatar los profesores de la casa durante el siglo XVII. De los que hemos logrado identificar, la mayoría procedía de España, Italia y Europa Central, pero no todos venían con sus estudios finalizados y con un título universitario, de allí que un porcentaje terminó el proceso de formación religiosa y profesional en Córdoba. Recordemos que los pocos que nacieron en territorio americano y concluyeron sus estudios en el período partían con el título bajo el brazo a sus lugares de origen, por lo tanto no fue usual que dictaran clases en esta casa; por otro lado, sabemos que los americanos tenían resistencia a ingresar en la Orden, lo que explica que los procuradores fueran cada tanto a Europa en busca de refuerzos de operarios.

En los comienzos del Colegio Máximo los primeros profesores fueron los PP. Juan de Albis, Baltazar Duarte, Alonso de Aguilera y Cristóbal de la Torre. ${ }^{20}$ Se considera que el P. Albis (1588-1630), fue el primer profesor de Filosofía. Sin embargo cabe acotar que, en 1610, cuando se iniciaron los estudios que como señalamos debieron interrumpirse para trasladarse a Chile se constató la existencia en Córdoba del P. Juan Pelin, nacido en Perú y discípulo del P. Juan de Atienza que había sido a su vez del P. Francisco Suárez, por lo que se supone que éste habría introducido el pensamiento suarista. Tiempo después el mismo Suárez solicitó que el P. Pelín fuese a enseñar esa disciplina, primero a Alcalá de Henares y, luego, a Madrid y Colonia.

Para 1614, asistían a clase unos treinta estudiantes, de los cuales catorce pertenecían a la Compañía y los demás eran convictores del Convictorio de S. Javier y externos. El P. Albis también utilizó en su cátedra de filosofía a Suárez, el pensador que más influyó en el Río de la Plata en esa centuria y en las siguiente: ${ }^{21}$ lo que fue

\footnotetext{
${ }^{20}$ GARRO, Juan M. (1884): Bosquejo Histórico de la Universidad de Córdoba, Córdoba, Imprenta de la Universidad, p. 19.

${ }^{21}$ PASTELLS, Pablo S.I.(1912):, Historia de la Compañia de Jesús en la provincia del Paraguay (Argentina, Paraguay, Uruguay, Perú, Bolivia y Brasil) según los documentos originales del ARCHIVO GENERAL DE INDIAS, Madrid, Librería general de Victorino Suárez, tomo I, p. 254. CATURELLI, Alberto. (2001): Historia de la Filosofia en la Argentina, 1600-2000, Buenos Aires, Editorial Ciudad Argentina, pp. 45 y ss. Entrado el siglo XVIII comenzó a leerse in voce en las clases el libro del jesuita español Antonio Rubio titulado Comentario a la lógica de Aristóteles, que se conoció también por el subtítulo Lógica Mexicana, por haberla escrito en ese país.
} 
reconocido por el P. Diego de Torres ese año en carta al prepósito general de la Orden cuando señaló que en todas las cuestiones se seguía al P. Suárez y, en algunas, al P. Gabriel Vázquez. Desde entonces la materia se dictó regularmente en sus aulas, en tanto era necesaria para seguir la carrera eclesiástica y obtener el título universitario. ${ }^{22}$ No obstante, hubo años como, por ejemplo en 1636-1637, que la cátedra cesó temporalmente por falta de oyentes. En 1619 el P. Albis cedió el dictado de la materia al P. Miguel de Ampuero quien continuó al frente de la misma hasta 1623. Carecemos de datos de los docentes que ocuparon la cátedra por un interregno de 37 años. Sabemos sí que para 1660 el sevillano P. Cristóbal Gómez (1610-1680), que había concluido sus estudios en la Universidad de Córdoba enseñaba en sus aulas dialéctica. Entre 1670 y 1672 fue rector de la institución y, luego entre 1695 y 1707 , se desempeñó como profesor de Moral y Teología $a^{23}$. Luego continuó al frente de la mencionada cátedra de filosofía el P. Cristóbal de Grijalba. Lauro Núñez ${ }^{24}$, Ignacio Frías y Francisco Burgés también detentaron el cargo a fines de esa centuria y a comienzos de la siguiente. ${ }^{25}$ Alberto Caturelli, estudioso de la historia de la filosofia en Argentina, sostiene que aun cuando no llegaron a nuestros días los primeros cursos manuscritos que se dictaron no es raro afirmar que todos ellos continuaron difundiendo la doctrina suarista.

También destacamos entre los docentes pioneros a los padres Francisco Vázquez y Juan Pastor, ${ }^{26}$ quienes dictaron clases de Teología a una docena de hermanos; de la misma manera lo hicieron Nicolás Mastrilli Durán ${ }^{27}$ y Vicente Fernández como profesor de Moral y Teología escolástica. En lo que respecta a la enseñanza de esta materia el P. Furlong recuerda la llegada al Río de la Plata, en 1621, del jesuita canario Francisco

\footnotetext{
22 PEÑA, Roberto. (1949): "Noticia sobre la enseñanza de la filosofía en la Universidad de Córdoba, durante el período jesuítico (1614-1767)", Actas del I Congreso Nacional de Filosofia, Mendoza, Universidad Nacional de Cuyo, Tomo III, p. 2103.

${ }^{23}$ El P. Gómez fue autor de varias obras, muchas pérdidas, aunque destacamos Elogia Societatis Iesu, in $4^{\circ}$, publicada por primera vez en Amberes en 1677. El P. Furlong consigna una traducción al español. Alberto CATURELLI, Historia de la Filosofia...Op. Cit, p.79.

${ }^{24}$ Lauro Núñez (1632-1719) fue profesor por treinta años de filosofia y de teología. En 1695 ejerció el cargo de rector de la Universidad.

${ }^{25}$ Burgués dictó clases por cinco años, período en el escribió diversos trabajos sobre temas de su especialidad.

${ }^{26}$ Juan Pastor nació en Fuentespalda, Teruel, el 18 de octubre de 1580. Ingresó a la Compañía con sólo 16 años y llegó a América en 1607 donde hizo sus últimos votos en 1614 en Santiago del Estero. Fue profesor, procurador en Europa en 1644 y provincial en el trienio 1651-1654. Falleció en Córdoba en 1658. STORNI Hugo, Catálogo de los Jesuitas de la Provincia del Paraguay (Cuenca del Plata) 1585-1768, Roma: Institutum Historicum S.I., 1980, p. 214.

${ }^{27}$ Nicolás Durán nació en Nola (Nápoles) en 1568 e ingresó a la Compañía en esa ciudad en 1583. Llegó al Perú en 1592 y fue ordenado en Lima en 1595, dio su cuarto voto en Julí (Puno-Perú) el 10 de octubre de 1604, lugar donde aprendió el quechua y el Aymará. Fue procurador de la provincia del Perú en Europa entre 1618-1621; Provincial del Paraguay entre 1623 y 1629 y del Perú (1630-34). Falleció en Lima el 14 de febrero de 1653 a los 85 años. IDEM, Ibídem, p. 179. COELLO DE LA ROSAAlexandre, "Los jesuitas y las misiones de frontera del Alto Perú: Santa Cruz de la Sierra (1587-1603)" en Revista Complutense de Historia de América, 2007, vol. 33, 151-175.
} 
Díaz Taño, ${ }^{28}$, quien en el ejercicio de la cátedra de Teología escribió quince cuadernos sobre la administración a los infieles de los sacramentos, particularmente el del matrimonio, y un tratado fundado en Derecho en defensa de la libertad de los naturales. Hubo además en toda la centuria otros padres que se dedicaron a una intensa vida misional, a la poesía o la música. En esta última especialidad descolló el francés Luis Berger quien llegó al Plata en 1617 y, en 1691, el italiano Antonio Sep. ${ }^{29}$ Sin embargo, el que sobresalió en esta materia en Córdoba fue Domingo Zípoli cuya obra inserta en el barroco tardío fue importante en la centuria siguiente. ${ }^{30}$

Hablar de cada uno de estos profesores requeriría un trabajo mayor; sólo deseo rescatar que en esta estructura educativa el rol que cumplieron fue más allá de enseñar en las aulas, en tanto también estaban obligados a prestar atención a la enseñanza religiosa y a la formación de los jóvenes según lo aconsejaban las reglas de la Compañía:

A los adolescentes que han sido confiados a la educación de la Compañía, fórmelos el profesor de modo que, juntamente con las letras vayan aprendiendo también las costumbres dignas de un cristiano. Dirija pues, su especial atención, tanto en las clases cuando se ofreciere la ocasión como fuera de ellas a preparar las tiernas mentes de los adolescentes para el servicio y amor de Dios y de las virtudes con que se les deba agradar. ${ }^{31}$

\footnotetext{
${ }^{28}$ Francisco Díaz Taño nació en una de las islas Canarias, en 1593. Estudió en Sevilla gramática y retórica y luego ingresó en la Orden de Loyola. Se embarcó para el Paraguay en enero de 1621 arribando a Buenos Aires dos meses después. Fue maestro de artes en Córdoba. Luego mantuvo una actividad intensa en la las misiones guaraníes. Fue destinado al Guairá. Después de recorrerlo, visitó la provincia de Guayaná y fundó la reducción de Candelaria. Compuso catecismos y vocabularios en la lengua de los indios lugareños. Fue interino del gobierno de la Orden en el Paraguay, por ausencia del padre Boroa. Regresó a España en 1637, para exponer a Felipe IV las necesidades de las misiones en estas provincias. Trasladóse, posteriormente, a Roma para tratar el mismo asunto con el superior general de la Compañía y con el Papa Urbano VIII. Volvió a América en 1640 con una bula, «plagada de graves censuras y penas, contra los que habían cometido y en adelante cometiesen los delitos que se representaban, contra la Compañía e indios de las Misiones». A su arribo a Río de Janeiro, y al poner en conocimiento dichas resoluciones de S. S. desde el púlpito del colegio de los jesuitas, los presentes se amotinaron y el populacho acometió contra él. Gracias a la mediación del gobernador, Salvador Correa de Saa, pudo sortear el problema. Retornó Díaz Taño a las misiones del Paraná y del Uruguay. Llamado a Asunción, con motivo de las disensiones entre los jesuitas y el obispo de Cárdenas, fue elegido, por segunda vez, procurador ante las cortes de Roma y Madrid. Regresó al viejo continente. En Madrid, Felipe IV resolvió que se impusiese perpetuo silencio a los émulos de la Compañía en estas provincias y que fuesen castigadas severamente las personas que se hubiesen señalado en contra de los misioneros. En 1657 el padre Díaz Taño desempeñaba el rectorado del colegio de la Asunción. FURLONG G. S.J. (1969): Historia social y cultural del Río de la Plata 1536-1810. El trasplante cultural: ciencia, Buenos Aires, TEA.

${ }^{29}$ El P. Sep nació en Caldaro, Italia el 22 de noviembre de 1655. Ingresó a la Compañía de Jesús en 1674 y obtuvo el sacerdocio en Augsburgo en 1687. Falleció en la reducción de San José el 13 de enero de 1733. STORNI, Hugo, Catálogo de...Op. Cit, p. 268.

${ }^{30}$ FURLONG, Guillermo S.J. (1968): se ocupó de este músico en: Doménico Zipoli, Córdoba, República Argentina, folleto.

${ }^{31}$ Reglas comunes a todos los profesores de las Facultades Superiores. Método y programa...Op. Cit.
} 
Para ello los padres incitaban a los estudiantes a cumplir con su función apostólica y social y para ello debían confesar y comulgar a menudo, además de realizar obras pías y cumplir con los ejercicios espirituales cada año y la renovación de los votos cada semestre. El jubileo de las 40 horas se celebraba con frecuencia y devoción y a él acudía la población a recibir los sermones y sacramentos. La Carta Anua de 16261627 recordó el fervor con que se observaba la religión en el Colegio: Ha sido muy particular la observancia y religión que he advertido en este Colegio y el fervor de nuestros estudiantes que juntan maravillosamente el de la devoción con las letras de que entre ambas se experimentan crecidos aumento.

Como los jesuitas eran profundos observadores y psicólogos sabían que para contar con la aceptación de los lugareños debían conocer su idioma, tarea no sencilla habida cuenta que en el Tucumán existían "gran variedad de idiomas difíciles, los cuales no era posible aprender a la vez y en poco tiempo», pero si querían evangelizar debían sobreponerse a esta dificultad y en ello pusieron mucho empeño no sólo los profesores de la región mediterránea sino los que habitaron en la zona oriental del Paraguay y en el resto de América. Era tan necesario el conocimiento de la lengua donde se iba a catequizar que el propio P. Antonio Ruiz de Montoya aconsejó que "ningún sacerdote haga la profesión solemne, aunque sea aptísimo para ello, si no supiere alguna lengua de indios". Pero también desde temprano se encargaron que los Padres aprendieran la lengua de los negros, lo que era importante habida cuenta que desde que tenían estancias se les recomendaba a los rectores que compraran hombres de esta raza para labrar las tierras y guardar el ganado ${ }^{32}$.

Varios fueron los docentes que, ya en sus cátedras o en su apostolado, trataron de dominar las lenguas vernáculas; entre estos sobresale el Padre Alonso de Barzana que llegó a entender más de trece lenguas, al tiempo que el Padre Torres escribió El arte y vocabulario de la lengua quechua y el P. Antonio Ruiz de Montoya su Catecismo y el Arte y vocabulario de la lengua guaraní, obras editadas en ese idioma por primera vez en España. La última sirvió de fuente para otros cronistas de la Compañía de Jesús, como del Techo o Charlevoix. ${ }^{33}$ En la centuria siguiente muchos otros continuarían con tareas similares. ${ }^{34}$

\footnotetext{
32 MORALES Martín, A mis manos...Op. Cit, p. 360.

${ }^{33}$ Arte, (y) vocabulario/ lengua / guarani / compuesto por el padre / Antonio Ruiz, de la Compañía de Iesus //dedicado a la soberana virgen María. (grabado en cobre de la virgen, idéntico al descrito en tesoro) con privilegio en Madrid por Juan Sánchez. año 1640. El Padre Provincial Pedro de Oñate sobre este tema escribía en la Carta Anua correspondiente al año 1617: “... El Padre Antonio ha hecho un Arte y Vocabulario de la lengua Guaraní y según me escriben los Padres [que están con el Padre Ruiz] parece que le ha concedido el Señor don de lenguas según la brevedad [o rapidez] y facilidad con que le habla...”. La obra tuvo sucesivas ediciones.

${ }^{34}$ Uno de ellos fue el P. MACHONI Antonio quien editó su Arte y Vocabulario de la lengua Lule y Tonocote, publicado por primera vez en 1732 y reeditado en 1877 por el Sr Juan M. Lársen. En el 2008 la obra fue editada en italiano a cura de Ricardo BADINI et al., Collana Scrittori Sardi, Pontificia Facoltá Teologica Della Sardegna, Cagliari. TARDIEU Jean Pierre, recordó como los jesuitas debían romper las barreras del rechazo y suscitar confianza entre la población negra y para ello necesitaban entender su idioma, lo que no siempre fue sencillo de lograr. Cfr. del autor "Los inicios del ministerio de negros en la provincia jesuítica del Paraguay" Anuario de Estudios Americanos, 62, 1, enero-junio, Sevilla (España), 2005, p.141-160.
} 
Pero, además, ellos estuvieron interesados por cuidar de la salud de la población estudiantil y local y, si bien no eran especialistas en farmacopea y en la ciencia de Galeno, ante la falta de médicos y medicinas dedicaron gran parte de su vasta y fecunda labor, al estudio y recolección de plantas vernáculas con el fin de establecer sus vinculaciones con la medicina. En estas ciencias a los primeros que hay que mencionar es al hermano Blas Gutiérrez $z^{35}$ y al Hno Marcos Villota. Luego la figura destacada es el Hno. Pedro de Montenegro de quien poseemos pocos datos biográficos, a pesar de la intensa actividad desplegada como médico y estudioso de la flora americana. Sabemos que nació en Galicia, España, en 1663 y ejerció medicina en el Hospital General de Madrid.

En 1679 se trasladó a América, para radicarse en la provincia del Paraguay, en calidad de enfermero de las misiones, residiendo un tiempo en el Colegio de Córdoba. La primera noticia de su presencia en estas tierras la menciona el P. Lozano en su obra Descripción corográfica del gran Chaco Gualumba. En 1705 encontramos un certificado extendido por el capitán de coraceros Andrés Gómez de la Quintana, en ocasión del sitio de la Colonia del Sacramento, para cuya empresa los jesuitas armaron y condujeron un ejército de 4.000 indios guaraníes, donde se señala que Montenegro actuó como cirujano para curar heridos junto con otros religiosos.

En Córdoba dio a conocer su magnífica obra titulada Materia Médica Misionera, un valioso códice donde analiza la flora americana y su aplicación y cualidades en el arte de curar. ${ }^{36}$ La obra llevaba en su portada la imagen de la Virgen de los Dolores a quien estaba dedicada pintada en tinta china. Fechada en 1710 incluía más de un centenar de ilustraciones de plantas medicinales que, en su mayoría, estaban tomadas de las obras de Guillermo Pisón y, especialmente de la comentada por Jacobo Bonti, De Indiae utriusque re naturali et medica, como el mismo Montenegro manifiesta al decir haberlas consultado y comprobado que «trahen varias plantas con los nombres de estas tierras de las cuales he traducido, y trasladado algunas, las que reconozco de mayores virtudes...». Pedro Andrés Mathiolo [Andrea Mattioli], Andrés de Laguna y Dioscórides fueron los autores que usó Montenegro para dar las explicaciones que insertó en los tres primeros capítulos cuando se ocupó de las propiedades curativas de algunas especies vegetales a las que agregó una nomenclatura botánica. Aunque reconoció que su inquietud por estudiar las mismas y, luego, elaborar medicamentos con ellas se debió a

\footnotetext{
35 Blas Gutiérrez, procedía de Vegacervera, León, donde había nacido en 1565. Ingresó a la provincia del Paraguay en 1614. Estuvo en Lima en casa del arzobispo Toribio de Mogrovejo y de allí pasó a Santiago de Chile donde después de realizar los ejercicios espirituales solicitó ingresar a la Orden. Sus últimos votos los dio en Córdoba en 1626 donde ejerció su oficio de barbero y cirujano. Curaba preferentemente a los miembros de la comunidad universitaria, particularmente desde 1633, cuando el General ordenó: "Que se excuse en cuanto pudiere el Hermano Blas, para acudir a curar seglares".

${ }^{36}$ Manuscrito del P. MONTENEGRO, S. J., Biblioteca Nacional de Buenos Aires - Sección Reservados - Documento Número 94- volumen, encuadernado en pergamino, de 460 páginas, las primeras 44 sin numerar, entre las que se incluye la hoja con el retrato de la Serenísima Reina de los Siete Dolores. $C f$. VERA DE FLACHS, María Cristina. (2009): De comadronas a Obstetras. La institucionalización del saber, Córdoba.
} 
que en estas tierras no existían boticas ni boticarios sino sólo curanderos a quienes más les cabía el nombre de matasanos o carniceros ignorantes. Esta actitud y su preocupación por aconsejar y enseñar a quienes practicaban el arte de curar advirtiendo sobre las cualidades, cantidad y modo de aplicación de sus recetas, revela su interés por contribuir a mejorar la salud de la población no sólo de Córdoba del Tucumán sino de Buenos Aires y Montevideo durante largo tiempo.

\section{Los estudiantes}

Creo que este trabajo no estaría completo si no nos preguntamos ¿a quién iban dirigidas las estrategias educativas? ¿Quiénes eran los estudiantes de la Universidad de Córdoba y cómo vivían en los claustros?

Cuando comenzó a funcionar la institución contaba con unos treinta alumnos. Muchos venían de lejos y una vez en la ciudad y hasta que se erigió el Colegio Monserrat los jóvenes debían alojarse en el Seminario o en casas particulares. Las elecciones de las familias respondían a los conocimientos previos de estas por parte de los progenitores. De allí que, a fines del XVII, acudían a sus aulas cuatro clases de estudiantes: los novicios de la Compañía, los alumnos del Seminario diocesano-trasladado a Córdoba desde Santiago del Estero en 1699 - los del Colegio Convictorio de Monserrat y los capistas o manteístas, alumnos externos que residían en casas particulares de la ciudad. En los primeros tiempos hubo quejas de parte de las autoridades civiles que el Colegio aprobaba a algunos estudiantes que no sabían nada. Por eso continuamente se recomendaba a los rectores que remediaran la situación poniendo empeño en aumentar los estudios temporales, como así también realizar los estudios tal como lo disponía el decreto 33 de la $7^{\text {a }}$. Congregación general que dispuso que los estudiantes debían oír tres años de artes y cuatro de teología sin que nadie pudiese dispensarlos de esta tarea.

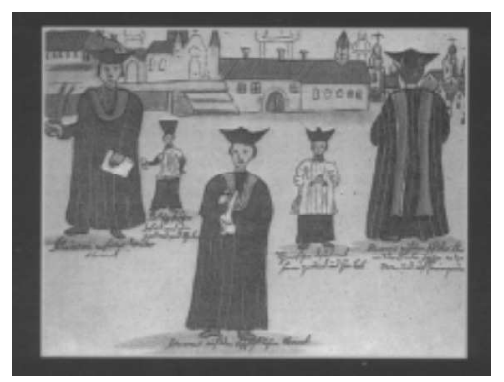

Dibujo de estudiantes universitarios de Córdoba - Argentina

Realizado por el padre Florián Paucke

Cabe recordar que negros, mulatos, zambos y mestizos que constituían un $60 \%$ de la población de Córdoba a finales de la centuria en estudio no tenían acceso a la educación superior. Sin embargo, las primeras Constituciones nada decían expresamente del problema de la limpieza de sangre para acceder a la misma, aunque luego la cuestión se plantearía en más de una ocasión. Este tema fue tratado por el claustro en 1710 quien fijó los requisitos sobre limpieza de sangre y legitimidad que debían cumplir los aspirantes a ingresar a la Universidad. Aunque cabe decir que

en más de una ocasión estos fueron burlados por los estudiantes que se veían favorecidos por la lejanía de sus lugares de origen, lo que impedía que los certificados llegaran a tiempo, por lo que en varios casos lograron concluir sus estudios sin problemas. Por su parte, los docentes debían fomentar la modestia de sus estudiantes a los que desde muy 
temprano se les fijó las condiciones requeridas de la vestimenta que debían llevar. El traje consistía en una sotana negra larga hasta los pies y sobre ella caía desde los hombres una estola púrpura. La parte que cubría el lado izquierdo tenía un pequeño escudo de plata en el que estaba grabado el nombre de Jesús. Un bonete de cuatro picos servía de ornato a la cabeza.

En 1668 el claustro preocupado por la vestimenta que ostentaban los jóvenes manifestó que no se permitiera el uso de trajes indecentes y profanos, que los mismos no llevaran adornos y que los que no cumplieran con la disposición debían ser expulsados de clase.

Michael Foucault ha señalado en varias oportunidades el papel de la disciplina en la enseñanza. En el caso de los jesuitas se puso especial cuidado en ella, al punto que el 19 de febrero de 1670, se dispuso que ningún estudiante debía salir -de día ni de noche a la calle- sin ir vestido decentemente con hábito clerical, aunque dentro de sus aposentos o en sus propios domicilios debían guardar igual compostura prohibiéndoles el uso de ropaje ostentoso que usaran zapatos picados o medias de otro color que no fuesen negras, pardo o morado y que los forros de las sotanas fuesen de tafetanes, las que debían ser de color negro, sin mangas con guarniciones, ni botones ni jubones que permitan ver lujos o colores. ${ }^{37}$ En caso de no cumplir con la orden el bedel estaba autorizado a quedarse con los zapatos o medias que no respondieran a las reglas. Y, en 1691, añadió que no trajesen sortijas, porque ese era un detalle propio de los señores doctores graduados y prohibió que los pajes los acompañaran dentro del establecimiento.

Además se aclaró que no podían salir después de las 21 horas en invierno y 22 horas en verano, caso contrario eran seriamente apercibidos: con 8 días de cepo y otros rigores la primera vez que burlasen la medida, con quince días la segunda y, en la tercera, eran despedidos del establecimiento irremisiblemente. De igual modo se les prohibía jugar al truco u otros juegos de cartas entre ellos o con otras personas de la casa o salir a las posadas con ese fin, siendo castigados de acuerdo a las reglas de la Compañía, con cárcel, cepo y otros instrumentos de castigo, conforme a la gravedad de las culpas. Obviamente se dejó establecido que las mujeres no podían ingresar al establecimiento educativo, limitándose incluso el tiempo de confesión para este sexo. Situaciones que fueron burladas en más de una oportunidad. Durante toda la centuria hubo críticas acerca de la licitud en que vivían los hermanos estudiantes, muchos de los cuales no tenían respeto a sus maestros, no ayunaban ni asistían a las misas reglamentarias y leían libros y poetas prohibidos, a la vez que escribían cartas sin licencia. Para más hubo períodos en los que estudiaban poco, por eso los docentes insistieron en que debían frecuentar las clases y, en marzo de 1683, como señalamos, se estableció que al final de cada año se examinara a todos los estudiantes en teología; además de demostrar sus conocimientos en predicación y como debían ejercitarse para provecho de las almas.

Casi al terminar la centuria del XVII el presbítero cordobés don Ignacio Duarte y Quirós efectuó la donación de su estancia Caroya y un solar en la ciudad de Córdoba

${ }^{37}$ A.G.U.C., Libro de Claustro, No 1 , fs. 77 v. 
como dotación y lugar de funcionamiento del Colegio Convictorio Nuestra Señora de Monserrat, además de otorgar seis becas a los alumnos que certificasen su pobreza. La apertura se efectuó en abril de 1693. El reconocimiento de la corona tardaría poco en llegar y a partir de entonces esta institución quedó ligada a la Universidad aunque careció por largo tiempo de un plan de estudios propios. A partir de entonces la matrícula se incrementó y a esta casa acudieron jóvenes de todas partes y desde lugares remotos con el fin de formarse para incorporarse a la magistratura eclesiástica y civil.

Los universitarios permanecían en Córdoba durante la temporada de estudios. En la mañana, después del desayuno, se repasaban las lecciones del día anterior ante la mirada atenta de un prefecto de estudio y, luego, partían a escuchar clases en la Universidad, ubicada en un edificio lindero.

Las vacaciones variaban según las costumbres, en el caso del Río de la Plata eran en los meses de verano (de diciembre a marzo). Había además días festivos como navidad, carnaval, semana santa, y pascua. En el verano pasaban sus días en la estancia de Caroya, incluso lo hacían los que vivían en la ciudad, en tanto preferían continuar en compañía de sus compañeros antes que regresar a la casa paterna. Los que venían de afuera obviamente eran los que más disfrutaban esa situación, pues lo usual era que no volvieran a su lugar de origen por largos años, solo lo hacían una vez que terminaban los estudios. En esa ocasión era común que cada día durante la cena hubiese en el comedor una disertación de uno de ellos acerca de un argumento propuesto de antemano. De esa manera los jóvenes iban practicando para hablar en público, a la vez que aprovechaban el momento para alabar a los santos y reprender los vicios. ${ }^{38}$

\section{CONCLUSIONES}

La documentación conservada sobre el siglo XVII nos permite afirmar que cualquiera fuese la cátedra que dictaron, los jesuitas cumplieron con el mandato de la Ratio e inculcaron los valores de la Orden siendo un ejemplo vivo de esa pedagogía que intentaba formar al hombre en ciencia y religión. Los que vinieron de Europa y se incorporaron a esta universidad debieron afrontar, en primer término, los retos que significaba el viaje a estas lejanas tierras de América, en una aventura espiritual comprometida con su fe y su apostolado y porqué no, con su juventud y espíritu aventurero. En segundo lugar, vencer los desafíos de enfrentar lo desconocido y, por último, al igual que lo ocurrido en otros colegios de Europa y América, poner todo el empeño en el objetivo de catequizar y enseñar. Para ejercer tal actividad era preciso que pusieran en práctica las estrategias de aprendizaje y las técnicas de la Ratio como la lección, concertación, ejercicios y repetición.

El mayor desafío de estos maestros tuvo como objetivo, a través de la educación, modelar al hombre americano procurando su formación intelectual y religiosa. La

\footnotetext{
38 VERA DE FLACHS María C. (1999): Finanzas, saberes y vida cotidiana en el Colegio Monserrat. Del Antiguo al Nuevo Régimen, Córdoba.
} 
primera basada en la enseñanza de la teología y la filosofía con el predominio de la escuela suarista y, la segunda, a través de la fe.

Otra característica digna de destacar de estos docentes es que, por lo general, residían poco tiempo en Córdoba, ya que era usual que se los destinara a otras misiones, sin embargo de ellos nos han quedado varios testimonios en tanto muchos fueron los que se animaron a escribir cartas, memoriales, vocabularios o textos de estudios sobre los más variados temas. Dichos escritos trascienden los relatos personales o los de la propia Compañía de Jesús y evidencian un profundo conocimiento del lugar que habitaron, en tanto nos informan de los progresos de la época, del estado de la educación, de la situación de las misiones, de la historia de la región, de las lenguas y tradiciones, del clima, de las riquezas naturales, etc., pero, también, de los problemas internos de la Orden, de la falta de vocaciones, de la relajación de los colegiales, de las materias que enseñaban y los textos utilizados. En fin, dieron cuenta de todo lo que hacía referencia a su sistema de enseñanza, lo que demuestra que dichos escritos son una cantera inagotable para los estudiosos del período; pero eso es otra historia.

\section{FUENTES}

\section{ARCHIVO GENERAL DE LA UNIVERSIDAD DE CÓRDOBA}

Libro de los Testimonios de grados en philosophia y theología que se dan en esta Universidad Bulas y Cédulas, 1621-1778-fs. 15, 34 y 45. Actas, 1664-1778.

Biblioteca del Colegio del Salvador- Buenos Aires

Cartas Anuas, 1652-1654. del Collegio de la Compañia de Jesús. Comienza en el año 1670.

Libro de Claustro, $\mathrm{N}^{\mathrm{o}} 1$.

\section{SELECCIÓN BIBLIOGRÁFICA}

AA.VV., La ratio Studiorum en América Latina. Su vigencia en la actualidad, Córdoba, Universidad Católica de Córdoba, 1956-2001.

AIZPURU Pilar Gonzalbo. (1989): La educación popular de los jesuitas, México, Universidad Iberoamericana.

CATURELLI Alberto, Historia de la Filosofia en la Argentina, 1600-2000, Buenos Aires, Editorial Ciudad Argentina.

DELFRANCO, José R. (1946): Establecimiento y progreso de los primeros estudios superiores en Córdoba. Años 1609 a 1879, 2da edición. Córdoba.

DEL REY FAJARDO, José. (1999): El alma de la Ratio Studiorum y el ámbito americano" en Jesuitas 400 años en Córdoba. III. Córdoba, Universidad Nacional - Universidad Católica - Junta Provincial de Historia.

DOMINIQUE, Julia. (1995): La cultura escolar como objeto histórico, en Historia de las Universidades Modernas. Métodos y Fuentes Margarita. MENEGUS y Enrique GONZALEZ, México, CESU, UNAM, 
GARCIA, Hilda. (1968): Índice de autoridades y profesores de la Universidad Nacional de Córdoba, Vol. I, 1670-1807, Mimeografiadas, Escuela de Archiveros, Facultad de Filosofia y Humanidades, Universidad de Córdoba.

GARRO, Juan M. (1884): Bosquejo Histórico de la Universidad de Córdoba, Córdoba, Imprenta de la Universidad.

GRACIA, Joaquín. (2006): Los Jesuitas en córdoba. Desde la colonia hasta la segunda Guerra Mundial, Tomo I. Universidad Católica, Colección Jesuitas, córdoba.

FURLONG Guillermo S.J. (1952): Nacimiento y desarrollo de la filosofía en el Río de la Plata. 1536-1810. Ed Kraft, Buenos Aires.

. (1933): Los jesuitas y la cultura rioplatense, Montevideo, Urta y Curbelo.

(1968): Doménico Zipoli, Córdoba, República Argentina, 1968, folleto.

(1969): Historia social y cultural del Río de la Plata 1536-1810. El

trasplante cultural: ciencia, Buenos Aires, TEA.

LÉRTORA MENDOZA, Celina Ana. (1979): La enseñanza de la filosofia en los tiempos de la colonia. Análisis de cursos manuscritos, Buenos Aires, Fundación para la Educación, la Ciencia y la Cultura.

LEONHARDT, Carlos SJ. (1927): Cartas anuas de la provincia del Paraguay, Chile y Tucumán, de la Compañia de Jesús, 1609-1614, (ed. et al), Buenos Aires, Facultad de Filosofia y Letras, Instituto de Investigaciones Históricas.

MAEDER, Ernesto. (1984): Las cartas anuas de la provincia jesuítica del Paraguay. 16371639, Buenos Aires, Fundación para la Educación, la Ciencia y la Cultura.

(1990): Cartas Anuas de la Provincia Jesuítica del Paraguay. 1632 a 1634, Buenos Aires, Academia Nacional de la Historia.

MESNARD, Pierre, (1978): A pedagogía dos jesuitas, en Os grandes pedagogistas. CHÂTEAU Jean São Paulo, Cia. Editora Nacional,

MONTERO TIRADO Jesús SJ. (1999): "El aprendizaje y la experiencia en la pedagogía ignaciana" en Jesuitas 400 años en Córdoba. III. Córdoba, Universidad Nacional Universidad Católica - Junta Provincial de Historia.

(2001) La Ratio Studiorum en América Latina. Su vigencia en la actualidad. Córdoba, Universidad Católica de Córdoba.

MORALES, Martín. (2005): A mis manos han llegado, Cartas de los PP. Generales a la antigua provincia del Paraguay (1608-1639), Madrid-Roma, Universidad Pontificia Comillas.

PASTELLS, Pablo S.I. (1912): Historia de la Compañia de Jesús en la provincia del Paraguay (Argentina, Paraguay, Uruguay, Perú, Bolivia y Brasil), Madrid, Librería general de Victorino Suárez.

PEÑA, Roberto. (1949): "Noticia sobre la enseñanza de la filosofía en la Universidad de Córdoba, durante el período jesuítico (1614-1767)", Actas del I Congreso Nacional de Filosofia, Mendoza, Universidad Nacional de Cuyo.

STORNI, Hugo. (1980): Catálogo de los Jesuitas de la Provincia del Paraguay (Cuenca del Plata) 1585-1768, Roma: Institutum Historicum S.I. 
TARDIEU, Jean Pierre. (2005): "Los inicios del ministerio de negros en la provincia jesuítica del Paraguay” Anuario de Estudios Americanos, 62, 1, enero-junio.

VAZQUEZ POSADA, Carlos S.J. (1999): La RATIO: sus inicios, desarrollo y proyección en Pontificia Universidad Javeriana. Colegio San Juan Berchmans.

. (2001): "La Ratio, sus inicios, desarrollo y proyección", en AA.VV., La Ratio Studiorum en América Latina. Su vigencia en la actualidad, Córdoba, Universidad Católica de Córdoba.

VERA, María Cristina. (1961): Dos siglos de gobierno, Tesis de Licenciatura en Historia, Córdoba. Inédita.

VERA, María Cristina. (1987): "El comportamiento de los claustros de la Universidad de Córdoba. 1664-1800", en Consejo Superior de Investigaciones Cientificas, Universidades Españolas y Americanas, España, Comissió per al V Centenari del Descobriment D'América, Generalitat Valenciana.

. (1995): "Para la Historia de la Universidad de Córdoba, (Argentina) 1614-1854", en Historia de las Universidades Modernas en Hispanoamérica. Métodos y fuentes. Universidad Autónoma de México. México.

. (1995): "Los jesuitas y la realidad rioplatense: el distrito de Córdoba', en História da Ciencia: O mapa do conhecimento. Expressao e Cultura. Universidade de Sao Paulo. Brasil.

(2002): "I Gesuiti in Sudamérica. Il caso de Cordoba" en Descubrir el Levante por el Poniente. I viaggi e le esplorazioni attraverso le collezione della Biblioteca Universitaria di Cagliari, Villanovaforru, Italia.

. (1996): Finanzas, saberes y vida cotidiana en el Colegio Monserrat. Del Antiguo al Nuevo Régimen, Córdoba, Copiar, 1999.

VERA DE FLACHS María Cristina y Remedios FERRERO MICO, (1996): Finanzas $y$ poder político en las universidades hispanoamericanas, Córdoba, Del Copista.

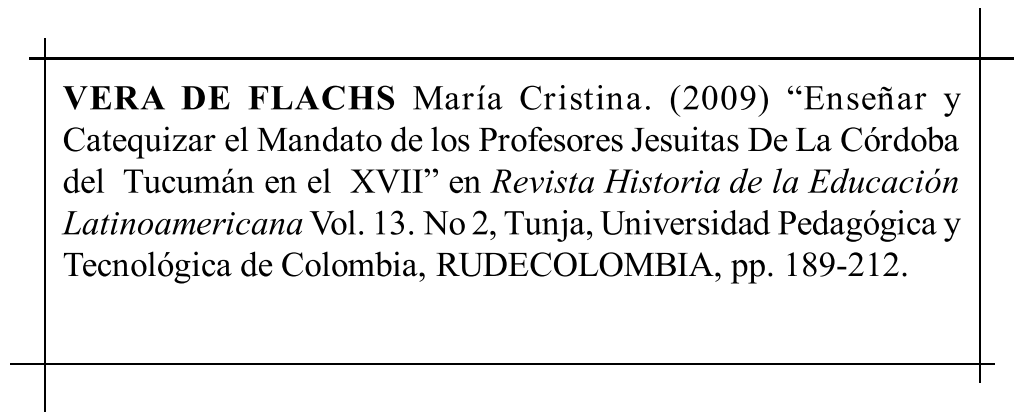

Rhela. Vol. 13. Año 2009, pp. 189 - 212 